\title{
Rad6 plays a role in transcriptional activation through ubiquitylation of histone H2B
}

\author{
Cheng-Fu Kao, ${ }^{1,3}$ Cory Hillyer, ${ }^{1,3}$ Toyoko Tsukuda, ${ }^{1}$ Karl Henry, ${ }^{2}$ Shelley Berger, ${ }^{2}$ \\ and Mary Ann Osley ${ }^{1,4}$ \\ ${ }^{1}$ University of New Mexico Health Sciences Center, Albuquerque, New Mexico 87131, USA; ${ }^{2}$ The Wistar Institute, \\ Philadelphia, Pennsylvania 19104, USA
}

Covalent modifications of the histone $\mathbf{N}$ tails play important roles in eukaryotic gene expression. Histone acetylation, in particular, is required for the activation of a subset of eukaryotic genes through the targeted recruitment of histone acetyltransferases. We have reported that a histone $\mathrm{C}$ tail modification, ubiquitylation of $\mathrm{H} 2 \mathrm{~B}$, is required for optimal expression of several inducible yeast genes, consistent with a role in transcriptional activation. H2B was shown to be ubiquitylated and then deubiquitylated at the GAL1 core promoter following galactose induction. We now show that the Rad6 protein, which catalyzes monoubiquitylation of $\mathrm{H} 2 \mathrm{~B}$, is transiently associated with the GAL1 promoter upon gene activation, and that the period of its association temporally overlaps with the period of $\mathrm{H} 2 \mathrm{~B}$ ubiquitylation. Rad6 promoter association depends on the Gal4 activator and the Rad6-associated E3 ligase, Bre1, but is independent of the histone acetyltransferase, Gcn5. The SAGA complex, which contains a ubiquitin protease that targets H2B for deubiquitylation, is recruited to the GAL1 promoter in the absence of H2B ubiquitylation. The data suggest that Rad6 and SAGA function independently during galactose induction, and that the staged recruitment of these two factors to the GAL1 promoter regulates the ubiquitylation and deubiquitylation of $\mathrm{H} 2 \mathrm{~B}$. We additionally show that both Rad6 and ubiquitylated H2B are absent from two regions of transcriptionally silent chromatin but present at genes that are actively transcribed. Thus, like histone $\mathrm{H} 3 \mathrm{Hysine} \mathbf{4}$ and lysine 79 methylation, two modifications that it regulates, Rad6-directed H2B ubiquitylation defines regions of active chromatin.

[Keywords: Rad6; gene activation; H2B ubiquitylation]

Received September 3, 2003; revised version accepted December 3, 2003.

Chromatin remodeling plays a key role in the regulation of eukaryotic gene expression through the activity of both ATP-dependent nucleosome remodeling factors and histone modifying activities (Belotserkovskaya and Berger 1999). Histone modifications such as acetylation, phosphorylation, and methylation occur on the core histone $\mathrm{N}$ tails, and they are frequently targeted to nucleosomes in the promoter regions of active genes (Grunstein 1997; Spencer and Davie 1999). These modifications are regulated by a large group of enzymes, often subunits of multiprotein factors that are themselves recruited to specific genes through interactions with site-specific DNA-binding proteins (Kuo et al. 2000; Peterson and Workman 2000; Bhaumik and Green 2001; Hassan et al. 2001; Larschan and Winston 2001). Although the histone $\mathrm{N}$ tails carry the majority of the modifications, the his-

\footnotetext{
${ }^{3}$ These authors contributed equally to this work.

${ }^{4}$ Corresponding author.

E-MAIL mosley@salud.unm.edu; FAX (505) 272-6029.

Article and publication are at http://www.genesdev.org/cgi/doi/10.1101/ gad.1149604
}

tone $\mathrm{H} 2 \mathrm{~A}$ and $\mathrm{H} 2 \mathrm{~B} \mathrm{C}$ tails are also posttranslationally modified. One such $\mathrm{C}$ tail modification, ubiquitylation, has also been linked to transcription (Bohm et al. 1980; West and Bonner 1980; Hensold et al. 1988; Davie et al. 1991; Bradbury 1992; Jason et al. 2002). Early work showed that nucleosomes in the $5^{\prime}$ regulatory regions of highly transcribed genes frequently contained elevated levels of ubiquitylated histones $\mathrm{H} 2 \mathrm{~A}$ and $\mathrm{H} 2 \mathrm{~B}$, suggesting that the modified histones play a role in transcriptional activation (Levinger and Varshavsky 1982; Barsoum and Varshavsky 1985; Nickel et al. 1989). In addition, recent studies have implicated ubiquitylated $\mathrm{H} 2 \mathrm{~B}$ in heterochromatic gene silencing and gene repression in yeast (Briggs et al. 2002; Dover et al. 2002; Ng et al. 2002; Sun and Allis 2002). However, the role of histone ubiquitylation in transcription is poorly understood. Because histones are primarily monoubiquitylated, which is not associated with protein turnover, the presence of ubiquitylated histones in chromatin has been postulated to confer a structural or signaling role (Briggs et al. 2002; Henry and Berger 2002; Jason et al. 2002; Sun and Allis 2002). 
Histone H2B is the only histone species in Saccharomyces cerevisiae currently known to be ubiquitylated (Swerdlow et al. 1990; Robzyk et al. 2000). Between 1 and $10 \%$ of total $\mathrm{H} 2 \mathrm{~B}$ in this organism is modified by the attachment of a single ubiquitin moiety, although this number could be higher if ubiquitin conjugation is a highly dynamic process as has been suggested (Busch and Goldknopf 1981; Seale 1981; Wu et al. 1981; Mueller et al. 1985; Robzyk et al. 2000; Sun and Allis 2002; Henry et al. 2003). The evolutionarily conserved ubiquitin conjugating enzyme, Rad6/Ubc2, catalyzes monoubiquitylation of H2B in yeast (Jentsch et al. 1987; Sung et al. 1988; Robzyk et al. 2000). Rad6 is a multifunctional protein with roles in postreplication DNA damage repair, meiosis, transcriptional silencing, and protein turnover (Montelone et al. 1981; Borts et al. 1986; Dohmen et al. 1991; Huang et al. 1997; Hoege et al. 2002; Turner et al. 2002). Its role in meiosis and transcriptional silencing appears to be directly related to its role in ubiquitylation of $\mathrm{H} 2 \mathrm{~B}$ because mutation of $R A D 6$ or loss of the $\mathrm{H} 2 \mathrm{~B}$ ubiquitylation site confer similar phenotypes in these two processes (Huang et al. 1997; Robzyk et al. 2000; Dover et al. 2002; Ng et al. 2002; Sun and Allis 2002). However, Rad6 targets a number of other substrates for modification besides $\mathrm{H} 2 \mathrm{~B}$, and its substrate specificity appears to be determined by its association with different E3 ubiquitin ligases (Kornitzer et al. 1994; Kaplun et al. 2000; Pickart 2001; Hoege et al. 2002). Until recently, there was no known E3 that specified H2B ubiquitylation by Rad6. The Brel protein, a RING finger protein with structural similarities to other E3 ubiquitin ligases, has emerged as an E3 that directs Rad6 to H2B (Joazeiro and Weissman 2000; Hwang et al. 2003; Wood et al. 2003). Deletion of $B R E 1$ globally reduces ubiquitylated $\mathrm{H} 2 \mathrm{~B}$ levels in yeast and confers several phenotypes that are similar to the loss of the H2B ubiquitylation site. Thus, Brel is predicted to play a role in the same cellular processes that are regulated by $\mathrm{H} 2 \mathrm{~B}$ ubiquitylation.

$\mathrm{H} 2 \mathrm{~B}$ ubiquitylation has been linked to transcription in yeast through its role in the trans-histone regulation of histone $\mathrm{H} 3$ lysine 4 and lysine 79 methylation (Briggs et al. 2002; Dover et al. 2002; Ng et al. 2002; Sun and Allis 2002). Both of these H3 methylation marks have been associated with transcriptionally active euchromatin, and their presence is reduced in regions of silent chromatin (Strahl et al. 1999; Bernstein et al. 2002; SantosRosa et al. 2002; van Leeuwen et al. 2002; Ng et al. 2003a). Moreover, a genomewide analysis of H3 lysine 4 methylation showed that lysine 4 trimethylation is concentrated at the $5^{\prime}$ regions of transcriptionally active genes ( $\mathrm{Ng}$ et al. 2003b). Given the role of H2B ubiquitylation in regulating $\mathrm{H} 3$ lysine 4 methylation, this suggested that the ubiquitin modification would also play a role in active transcription. In support of this view, we recently reported that monoubiquitylation of $\mathrm{H} 2 \mathrm{~B}$ is required for the optimal expression of two highly inducible yeast genes, GAL1 and SUC2 (Henry et al. 2003). Upon induction of the GAL1 gene, H2B was found to be sequentially ubiquitylated and then deubiquitylated at the GAL1 core promoter prior to the significant accumula- tion of transcripts. Deubiquitylation was shown to be controlled by the activity of the ubiquitin protease, Ubp8, a stoichiometric subunit of the SAGA coactivator, which is one of the earliest factors recruited to the $G A L$ promoter following galactose induction (Sanders et al. 2002; Bryant and Ptashne 2003). However, the requirements for $\mathrm{H} 2 \mathrm{~B}$ ubiquitylation were not defined in this study. In this report, we investigated the role of Rad6 in the ubiquitylation of $\mathrm{H} 2 \mathrm{~B}$ at the GAL1 gene during galactose activation. We found that, like SAGA, Rad6 was also recruited to the GAL1 promoter, but, unlike SAGA, it remained there only transiently. Rad6 promoter association required the Gal4 activator and the Rad6-associated E3, Bre1, and thus in addition to its role in DNA damage repair, Rad6 can also be classified as a transcriptional coactivator. The period of Rad6 promoter association closely paralleled the period of $\mathrm{H} 2 \mathrm{~B}$ ubiquitylation and appeared to precede the recruitment of SAGA. This suggests that the staged recruitment of Rad6 and SAGA controls the ubiquitylation and deubiquitylation of $\mathrm{H} 2 \mathrm{~B}$ at the GAL promoter. We also show that $\mathrm{H} 2 \mathrm{~B}$ ubiquitylation, like the two $\mathrm{H} 3$ methylation marks that it controls, is generally excluded from silent chromatin but present in regions of transcriptionally active euchromatin. Thus, H2B ubiquitylation can also be considered as a mark of active chromatin.

\section{Results}

Rad6 is transiently associated with the GAL1 promoter

The GAL genes provide an excellent model for gene activation in eukaryotes. The genes are repressed in glucose-containing medium and induced when cells are shifted to the presence of galactose (Johnston and Carlson 1992; Trumbly 1992; Johnston et al. 1994). Upon gene activation, repression by Mig1/Tup1-Ssn6 is first relieved, and then a cascade of transcription factor recruitment to the GAL promoters is initiated by the enhanced binding of the Gal4 activator to UAS sites in each promoter. Studies performed with the GAL1-GAL10 genes have shown that one of the earliest factors to be recruited is the SAGA histone acetyltransferase complex, which requires Gal4 for its association with the GAL promoter (Bhaumik and Green 2001; Larschan and Winston 2001; Bryant and Ptashne 2003). Subsequently, Mediator, TBP, and RNA polymerase II become associated with the core promoter, and transcription initiates (Bryant and Ptashne 2003).

In addition to these factors, we recently showed that $\mathrm{H} 2 \mathrm{~B}$ ubiquitylation contributes to the maximal transcription of the GAL genes (Henry et al. 2003). In the absence of this histone modification, the levels of GAL1 transcript were reduced following galactose activation. Consistent with a role in the initiation of GAL1 transcription, H2B was found to be transiently ubiquitylated at the GAL1 core promoter at a time that preceded the accumulation of GAL1 mRNA. We therefore asked if Rad6, which directs monoubiquitylation of $\mathrm{H} 2 \mathrm{~B}$, was also recruited to the $G A L$ promoter upon gene induction 
using the method of chromatin immunoprecipitation (ChIP; Orlando and Paro 1993; Hecht et al. 1996; Kuo and Allis 1999). ChIP was carried out during growth in glucose medium and at 30-min intervals after a shift to galactose medium in a yeast strain that contained an HA epitope-tagged RAD6 gene (Fig. 1A). The data showed that Rad6 was dynamically associated with the GAL1 UAS. Maximal occupancy occurred at 30-60 min after the shift to galactose, and by 120 min Rad6 binding to the GAL1 UAS was substantially reduced. The peak of association significantly preceded the appearance of GAL1 transcripts as measured by Northern blot analysis (Fig. 1A, inset), suggesting that Rad6 recruitment to the UAS regulates a very early event in GAL1 transcription. This event is most likely the Rad6-mediated ubiquitylation of $\mathrm{H} 2 \mathrm{~B}$, as the period of Rad6 association with the UAS and the period of $\mathrm{H} 2 \mathrm{~B}$ ubiquitylation at the core promoter almost exactly coincided (Fig. 1B).

Next, we determined the genetic requirements for
Rad6 association with the GAL1 promoter. We first asked if Rad6 recruitment occurred in an $h t b 1-K 123 R$ mutant, where H2B is not ubiquitylated (Fig. 1C). In this mutant, Rad6 also transiently associated with the $G A L$ promoter, although the peak of association was delayed by $\sim 30 \mathrm{~min}$ and the drop in promoter binding occurred somewhat more slowly. Thus, prior ubiquitylation of $\mathrm{H} 2 \mathrm{~B}$ is not a prerequisite for Rad6 promoter association, although it may control the kinetics of Rad6 recruitment and departure from the promoter. Because the Gal4 activator interacts in vivo and in vitro with a number of chromatin remodeling/modifying activities and is required to bring SAGA to the GAL1 promoter in vivo (Melcher and Johnston 1995; Bhaumik and Green 2001; Larschan and Winston 2001; Carrozza et al. 2002), we next asked if it was also required to bring Rad6 to GAL1. ChIP was performed in a gal4s strain, and the results showed that Rad6 did not occupy the GAL1 promoter when the activator was absent (Fig. 2A). Rad6 was re-
A. ChIP: $\alpha-$ HA (Rad6)

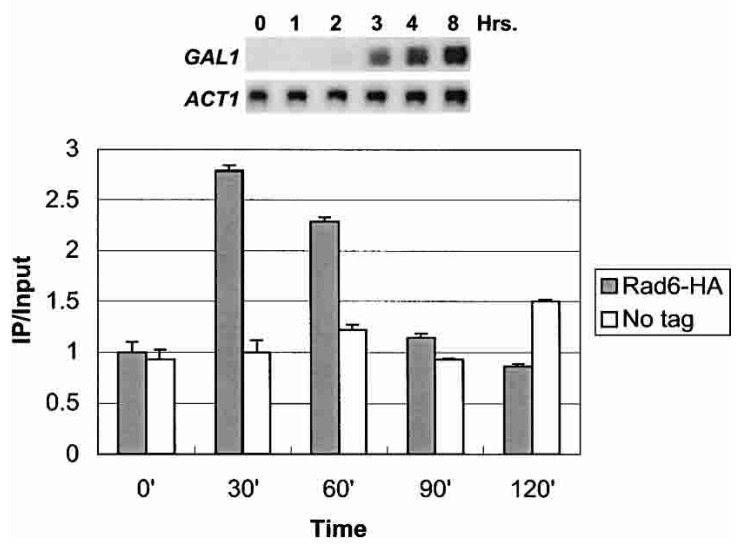

B. ChDIP: $\alpha$-Flag (H2B); $\alpha-H A$ (ubiquitin)

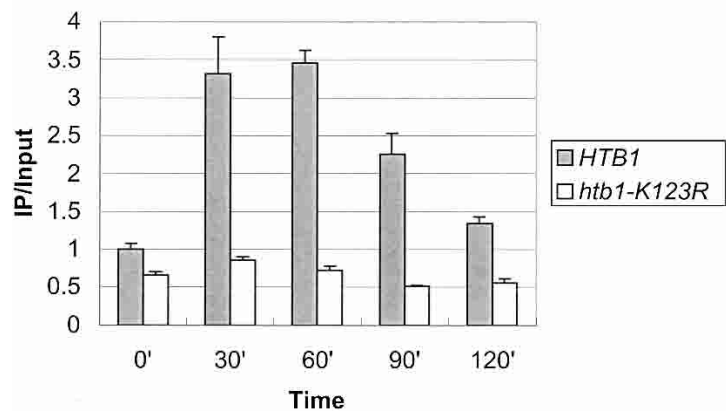

C. ChIP: $\alpha-H A$ (Rad6)

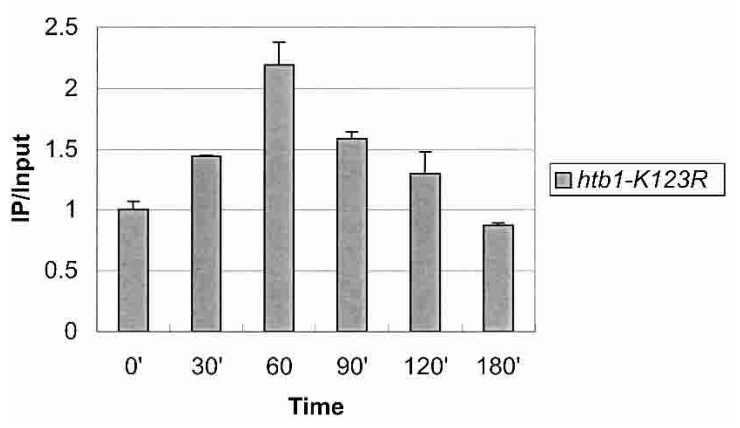

D. ChIP: $\alpha-\mathrm{HA}$ (Rad6)

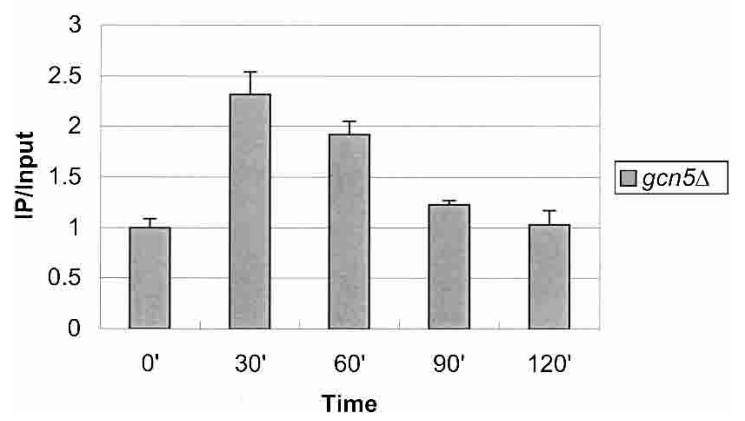

Figure 1. Rad6 is transiently associated with the GAL1 promoter. (A) Strains YKH010 (Rad6-HA HTB1) and JR5-2A (No tag control HTB1) were grown in YPD medium and shifted to YP $+2 \%$ galactose medium, and chromatin immunoprecipitation (ChIP) was performed with anti-HA antibodies at the indicated times. PCR analysis in real time was used to measure the abundance of GAL1 UAS sequences in immunoprecipitated (IP) DNA relative to input DNA. The Northern blot inset is from Figure 7A. (B) Strains YKH045 (Flag-HTB1; HA-ubiquitin) and YKH046 (Flag-htb1-K123; HA-ubiquitin) were grown as described in panel A. Chromatin double immunoprecipitation (ChDIP) was sequentially performed with anti-Flag and anti-HA antibodies, and PCR in real time was used to measure the abundance of GAL1 core promoter sequences in the IP DNA ( $\alpha$-HA) relative to input DNA ( $\alpha$-Flag). The data were normalized to the IP/Input ratios for INT- $V$, which is not regulated by galactose and thus served as a control. $(C, D)$ Strains YKH017 (Rad6-HA $h t b 1-K 123 R$ ) and YCH001 (Rad6-HA HTB1 gcn5s) were grown as described in panel A, and ChIP was performed with anti-HA antibodies, followed by PCR analysis in real time using primers that detect the GAL1 UAS sequences. 
A.

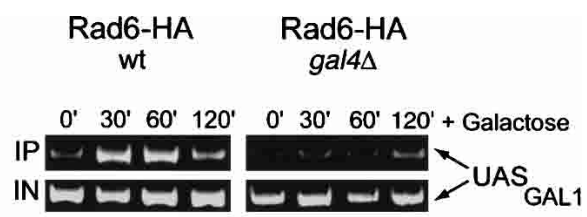

B.

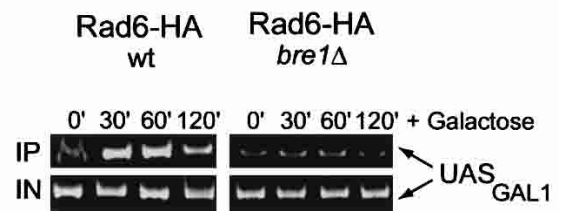

Figure 2. Rad6 recruitment to the GAL1 promoter requires the Gal4 activator and the Bre1 E3 ligase. After a shift to $\mathrm{YP}+$ galactose medium, ChIP and conventional PCR analysis were carried out in a RAD6-HA HTB1 strain that contained

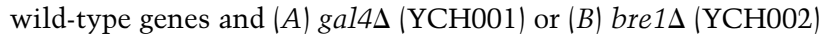
deletions. The PCR reactions were electrophoresed on a $10 \%$ acrylamide gel, which was stained with ethidium bromide. All reactions were performed in the linear range of amplification.

cently reported to be in a complex with Bre1, an E3 ligase that directs Rad6 to monoubiquitylate $\mathrm{H} 2 \mathrm{~B}$ and is required for the presence of Rad6 at the constitutive PMA1 promoter (Hwang et al. 2003; Wood et al. 2003). The binding of Rad6 to the GAL1 UAS was also significantly reduced in a bre $1 \Delta$ mutant, indicating that a Rad6-Bre1 complex is likely to be recruited to GAL1 (Fig. 2B). Finally, Rad6 continued to show transient occupancy of the GAL1 promoter in a $g c n 5 \Delta$ mutant, indicating that histone acetylation is also not required for its recruitment (Fig. 1D). Together, the results suggest that in response to galactose activation, the Gal4 activator recruits the Rad6-Bre1 complex to the GAL1 UAS, where it results in the ubiquitylation of $\mathrm{H} 2 \mathrm{~B}$ at the core promoter. BEcause we have shown that $\mathrm{H} 2 \mathrm{~B}$ ubiquitylation is important for the maximal transcription of GAL1 (Henry et al. 2003), the data indicate that Rad6, like SAGA, functions as a transcriptional coactivator at the GAL1 gene.

\section{SAGA and Rad6 show different patterns of GAL1 promoter association}

The SAGA complex is one of the earliest factors recruited to the GAL genes following galactose induction, and it has two known roles at the GAL1 core promoter (Bryant and Ptashne 2003). First, the Ubp8 subunit, a ubiquitin protease, targets $\mathrm{H} 2 \mathrm{~B}$ for deubiquitylation (Henry et al. 2003), and second, the Spt3 subunit is required for recruitment of the TATA-binding protein, TBP (Dudley et al. 1999; Bhaumik and Green 2001, 2002; Larschan and Winston 2001). Because deubiquitylation of H2B closely follows its ubiquitylation, we compared the recruitment of SAGA to that of Rad6 following a shift from glucose to galactose medium. As measured by ChIP in a strain containing a Gen5-HA protein, SAGA showed increased association with the GAL1 UAS over the time course of the experiment (Fig. 3A), similar to the pattern we recently reported (Henry et al. 2003). At $120 \mathrm{~min}$ after the shift to galactose medium, a time when Rad6 was no longer associated with the promoter (Fig. 1A), SAGA was almost four times more concentrated at the GAL1 UAS than it was in glucose medium. Thus, the two coactivators show very different patterns of association with the GAL1 promoter: Rad6 binds transiently, whereas SAGA remains bound once it is recruited. To determine if Rad6 binds before SAGA, we examined the promoter association of the two factors at shorter time intervals following a shift from raffinose to galactose medium, which leads directly to GAL1 activation (Fig. 3C). The data show that Rad6 was again transiently associated with the GAL1 promoter. Moreover, Rad6 reached its maximal occupancy of the UAS earlier than SAGA (15-30 min vs. 30-90 min), supporting the view that Rad6 may be the first factor recruited to the GAL1 UAS upon galactose induction. As in the glucoseto-galactose shift, the period of Rad6 association preceded the maximal accumulation of GAL1 transcripts, consistent with a role for Rad6 recruitment in transcriptional activation (data not shown). Finally, we asked if Rad6-directed ubiquitylation of $\mathrm{H} 2 \mathrm{~B}$ were required for SAGA association with the GAL1 promoter by performing ChIP in an $h t b 1-K 123 R$ mutant. SAGA continued to accumulate at the GAL1 UAS in the absence of both the H2B ubiquitylation site and the Bre1 E3 ligase (Fig. 3A; data not shown). As previously noted, Gcn5-associated H3 Lys 9/Lys14 acetylation levels did not change during GAL1 induction (Bhaumik and Green 2001; Larschan and Winston 2001), and here we show that the htb1K123R mutation has no effect on this histone modification (Fig. 3B). Thus, we propose that Rad6 precedes SAGA at the GAL1 promoter, but that SAGA is recruited to the promoter independently of Rad6-mediated H2B ubiquitylation.

\section{Histone $H 2 B$ is transiently ubiquitylated at the PHO5 promoter}

To determine if $\mathrm{H} 2 \mathrm{~B}$ ubiquitylation plays a role in the expression of other inducible genes, the levels of the modified histone were also examined during activation of the PHO5 gene. This gene is regulated by an entirely different mechanism from GAL1, but like GAL1, PHO5 transcription also shows a modest dependence on $\mathrm{H} 2 \mathrm{~B}$ ubiquitylation (see Fig. 7A, below; Vogel et al. 1989; Svaren and Horz 1997). Using the chromatin double immunoprecipitation assay, ubiquitylated $\mathrm{H} 2 \mathrm{~B}$ was found to transiently accumulate at the $\mathrm{PHO} 5$ core promoter after phosphate was depleted from the medium (Fig. 4). The level of ubiquitylated H2B peaked $\sim 2.3$-fold above the repressed level at $90 \mathrm{~min}$ after the shift and declined to the uninduced level by $120 \mathrm{~min}$, a time that preceded the maximal accumulation of PHO5 transcripts. This rise strictly depended on the presence of the H2B ubiquitylation site and was specific to the PHO5 gene, as the levels of ubiquitylated $\mathrm{H} 2 \mathrm{~B}$ remained unchanged at two 
Kao et al.

\section{A. ChIP: $\alpha-H A(G c n 5)$}

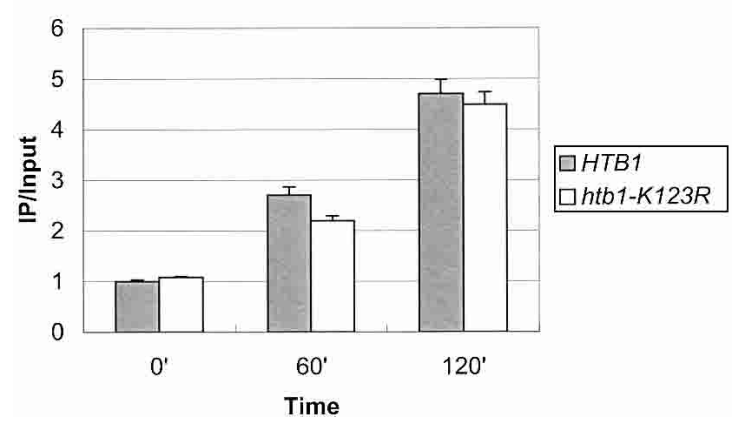

B. ChIP: $\alpha-\mathrm{H} 3 \mathrm{~K} 9 / \mathrm{K} 14$ acetylation

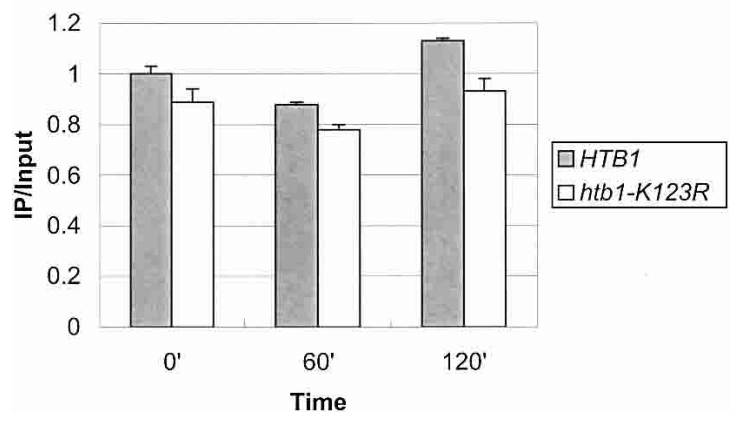

C.
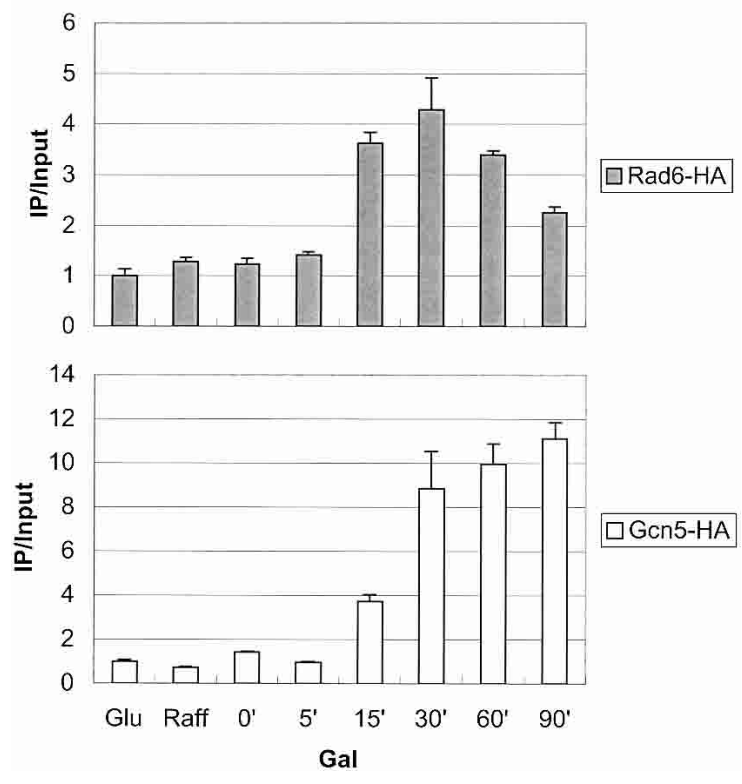

Figure 3. Rad6 and SAGA show different patterns of association with the GAL1 promoter. (A) Strains carrying Gcn5-HA and either HTB1 (YKH012) or htb1-K123R (YKH019) were subjected to ChIP and PCR analysis in real time as described in the legend to Figure $1 \mathrm{~A}$ before and after a shift to YP + galactose medium. $(B) \mathrm{ChIP}$ was performed with anti-H3 K9/K14 acetylation antibodies in strains Y131 (HTB1) and Y133 (htb1-K123R) before and after a shift to YP + galactose medium, and the DNA was analyzed by PCR in real time to determine the levels of $\mathrm{H} 3$ acetylation at the $G A L 1$ core promoter. $(C)$ ChIP was performed with anti-HA antibodies in strains YKH010 (Rad6-HA HTB1) and YKH0112 (Gcn5-HA HTB1) during growth in YPD (Glu), after $2 \mathrm{~h}$ in YP $+2 \%$ raffinose (Raff), and at the indicated times after galactose was added to a final concentration of $2 \%$. PCR in real time was performed to measure the association of Rad6 and Gen5 with the GAL1 UAS. The data in each panel were normalized to the IP/Input ratio of the INT-V control sequences.

intergenic regions under the same growth conditions (Fig. 4; data not shown). Thus, the data suggest that H2B ubiquitylation and deubiquitylation may play general roles in the initiation of transcription following gene activation.

\section{Distribution of H2B ubiquitylation}

To determine if $\mathrm{H} 2 \mathrm{~B}$ ubiquitylation was restricted to transcribed genes, the levels of the modified histone were measured at different regions of the yeast genome by a chromatin double immunoprecipitation assay or ChDIP (Fig. 5A). Besides the induced GAL1 and PHO5 genes, two constitutively transcribed genes, ACT1 and $P M A 1$, also contained ubiquitylated $\mathrm{H} 2 \mathrm{~B}$ at their promoters, albeit at lower relative amounts. In addition to these transcribed genes, two ORF-free intergenic regions on chromosomes V and XVI contained relatively high levels of the H2B modification, whereas two regions of silenced chromatin, TELVI-R and HMRa, had the lowest levels of ubiquitylated H2B. This distribution is remarkably similar to the pattern of H3 Lys 79 methylation at the same genomic regions, which is dependent on H2B ubiquitylation (data not shown). Together, the results suggest that ubiquitylated H2B, like H3 Lys 4 and Lys 79 methylation, may be broadly distributed in transcriptionally active euchromatin and excluded from heterochromatin-like regions (Bernstein et al. 2002; Ng et al. 2003a,b). Next, we measured Rad6 association with the same genomic regions by ChIP (Fig. 5B). Like ubiquitylated H2B, Rad6 was present at the promoters of each of the induced or constitutive genes, but absent from the two regions of silent chromatin. Surprisingly, Rad6 was also absent from the two ORF-free regions, even though these regions contain relatively high levels of H2B ubiquitylation. This suggests that the ubiquitylated species may be differentially stabilized depending on its genomic location. For example, if the ORF-free regions are not transcribed, then there may be no targeted recruitment of a ubiquitin protease, such as occurs at the GAL1 promoter upon SAGA association (Henry et al. 2003). Using similar reasoning, these data also imply that Rad6 may ubiquitylate $\mathrm{H} 2 \mathrm{~B}$ by both targeted and untargeted mechanisms.

We then asked how H2B ubiquitylation was distributed at an individual transcribed gene. We predicted that 


\section{ChDIP: $\alpha$-Flag (H2B); $\alpha$-HA (ubiquitin)}

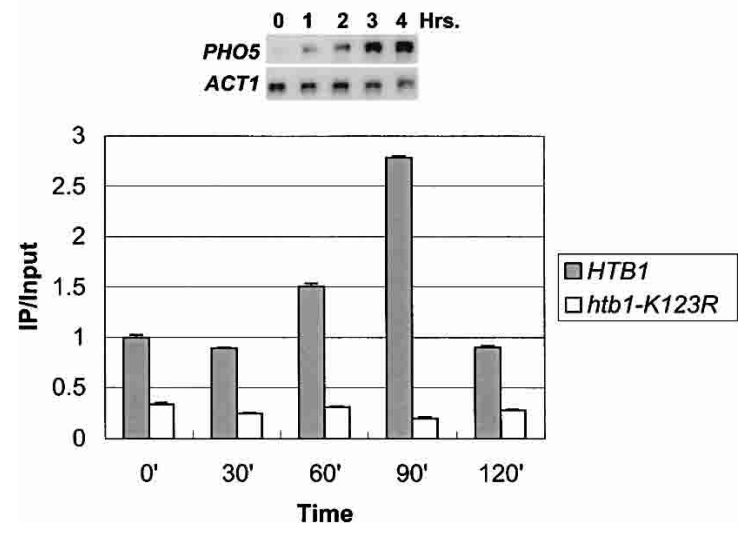

Figure 4. $\mathrm{H} 2 \mathrm{~B}$ is transiently ubiquitylated at the PHO5 core promoter. ChDIP was carried out in strains YKH045 (FlagHTB1) and YKH046 (Flag-htb1-K123R) during growth in YPD medium and at 30-min intervals after a shift to a medium lacking inorganic phosphate, and extracted DNA was analyzed by quantitative PCR in real time to determine the levels of $\mathrm{H} 2 \mathrm{~B}$ ubiquitylation at the PHO5 core promoter. The data were normalized to the INT-V IP/Input ratios. The Northern blot inset is from Figure 7A.

it might be associated only with the core promoters of active genes, consistent with a role in transcription initiation. We addressed this question at the GAL1 gene by performing ChDIP in glucose-repressed and galactose-induced cells, using PCR primers that corresponded to the GAL1 core promoter, 5' ORF, and 3' ORF regions (Fig. 6A). Surprisingly, under repressed conditions, the 3' ORF region was found to contain a significant level of ubiquitylated $\mathrm{H} 2 \mathrm{~B}$, whereas the 5' ORF region and core promoter had progressively lower levels of the modified histone. However, after $60 \mathrm{~min}$ of galactose induction, the level of ubiquitylated $\mathrm{H} 2 \mathrm{~B}$ rose disproportionately at the $5^{\prime}$ end of GAL1, resulting in an approximately equal distribution of the modified histone across the promoter and ORF. Thus, H2B ubiquitylation is, in fact, targeted to the 5' end of GAL1 upon gene induction, consistent with a role in transcription initiation, but its presence throughout the gene suggests that it might also play a role in transcription elongation. When the distribution of Rad6 was examined at the same GAL1 regions by ChIP, little Rad6 was found to be associated with any region of the gene when cells were grown under repressing conditions (Fig. 6B). However, after galactose induction, 2.5 -fold more Rad6 was present at the GAL1 UAS and core promoter as well as at the two ORF regions. This is consistent with Rad6 and ubiquitylated H2B having a role in both transcription initiation and transcription elongation.

H2B ubiquitylation plays an overlapping role with chromatin remodeling factors

Although our data indicate that $\mathrm{H} 2 \mathrm{~B}$ ubiquitylation might be fairly widespread in euchromatin, we have pre- viously shown that the absence of the ubiquitylated species confers relatively modest effects on cell growth and gene expression (Henry et al. 2003). This suggests that the $\mathrm{H} 2 \mathrm{~B}$ modification might be functionally redundant with other histone modifying activities or nucleosome remodeling factors. In support of this view, we have noted two synthetic phenotypes in double mutants constructed between the $h t b 1-K 123 R$ and $g c n 5 \Delta$ or $s n f 5 \Delta$ alleles. First, $h t b 1-K 123 R$ snf5s double mutants grow significantly more slowly than either single mutant, whereas $h t b 1-K 123 R$ gcn5 $\Delta$ double mutants show a Ts- growth defect (data not shown). Second, transcription of several inducible genes is severely compromised in the double mutants (Fig. 7). Whereas transcription of the GAL1, PHO5, and SUC2 genes was reduced less than twofold in $h t b 1-K 123 R$ single mutants (Fig. 7A), transcription of the SAGA-dependent GAL1 and PHO5 genes and the Swi/Snf-dependent SUC2 gene was almost abolished in $h t b 1-K 123 R$ gcn5s and htb1K123R snf5 $\Delta$ double mutants, respectively (Fig. 7B). This phenotype is unrelated to the growth defects of the double mutants because expression of the SAGA-dependent INO1 gene and the Swi/Snf- and SAGA-dependent $\mathrm{HO}$ gene was unaffected in the same double mutant backgrounds (data not shown). Thus, H2B ubiquitylation becomes very important for the expression of specific genes in the absence of either Gcn5-dependent histone acetylation or ATP-dependent nucleosome remodeling, indicating that the $\mathrm{H} 2 \mathrm{~B}$ modification plays a functionally overlapping role with these two chromatin remodeling factors.

\section{Discussion}

In this study, we show that upon galactose induction, Rad6 is dynamically associated with the GAL1 UAS, leading to a concomitant transient accumulation of ubiquitylated $\mathrm{H} 2 \mathrm{~B}$ at the core promoter. The temporal overlap between Rad6 promoter association and H2B ubiquitylation suggests that the $\mathrm{H} 2 \mathrm{~B}$ modification is a direct consequence of the recruitment of $\operatorname{Rad} 6$ to the GAL1 promoter. Both the Gal4 activator and the Rad6-associated E3 ligase, Bre1, are required for Rad6 to bind to the GAL1 promoter, suggesting that Gal4 might directly recruit the Rad6-Brel complex. Because we have previously shown that $\mathrm{H} 2 \mathrm{~B}$ ubiquitylation plays a role in the activation of GAL1 transcription (Henry et al. 2003), the data indicate that Rad6 functions as a transcriptional coactivator in addition to its role in mediating postreplication DNA repair. $\mathrm{H} 2 \mathrm{~B}$ ubiquitylation was also found to increase transiently at the PHO5 core promoter upon gene activation, suggesting that the dynamic regulation of this $\mathrm{H} 2 \mathrm{~B}$ modification could play a general role in the initiation of transcription. Consistent with the idea that $\mathrm{H} 2 \mathrm{~B}$ ubiquitylation is associated with transcriptionally active chromatin, the modified form of $\mathrm{H} 2 \mathrm{~B}$ was present at the promoters of both induced and constitutive genes but absent from regions of silent chromatin (Fig. 6A). 
Figure 5. Distribution of ubiquitylated H2B. $(A)$ ChDIP was sequentially performed with anti-Flag and anti-HA antibodies in strains YKH045 (FlagHTB1) and YKH046 (Flag-htb1-K123R) after growth in YPD medium. PCR in real time was used to measure the level of $\mathrm{H} 2 \mathrm{~B}$ ubiquitylation at two transcriptionally silenced regions (TELVI-R and $H M R a)$, two ORF-free intergenic regions (INT-V and INT-XVI), the core promoters of two highly transcribed constitutive genes (PMA1 and ACT1), and the core promoters of the GAL1 and PHO5 genes after induction with galactose or no phosphate, respectively. (B) ChIP was performed with anti-HA antibodies in strains YKH010 (Rad6-HA HTB1) and JR5-2A (No tag HTB1) grown in YPD or induced with galactose, and PCR in real time was used to measure the level of Rad6-HA at the genomic regions described in panel $A$.

\section{Rad6 and SAGA are sequentially recruited to the GAL1 promoter}

Previous studies have shown that galactose induction is accompanied by the sequential appearance of proteins at the GAL1-GAL10 promoter, with the SAGA complex being the first factor to bind after the Gal4 activator (Bhaumik and Green 2001; Larschan and Winston 2001; Bryant and Ptashne 2003). In this study, we have identified Rad6 as a new protein that appears at the GAL1 promoter during galactose activation. Using ChIP, we found that the binding of Rad6 appears to temporally precede that of SAGA (Fig. 3C), suggesting that Rad6 may, in fact, be the earliest factor to associate with the GAL1 promoter. Moreover, the recruitment of SAGA also appears to be independent of Rad6's activity in H2B ubiquitylation because Gcn5-HA associates with the GAL1 promoter in both an htb1-K123R and bre $1 \Delta \mathrm{mu}-$ tant (Fig. 3B; data not shown). Thus, it is likely that Rad6 and SAGA are independently recruited to the GAL1 UAS, with Rad6 binding first. Both factors bind to the GAL promoter only if the activator Gal4 is present (Fig. 2A; Bhaumik and Green 2001; Larschan and Winston 2001; Bryant and Ptashne 2003). SAGA interacts with Gal4 in vitro (Bhaumik and Green 2001), but we do not know whether Rad6 contacts Gal4 directly, or whether Rad6 and SAGA might contact the same surface of the activator. Brel is also required for Rad6 association with the GAL1 UAS (Fig. 2B), and we therefore assume that a Rad6-Bre1 complex is recruited to the GAL1 promoter. Thus, Brel could also provide a binding surface for Gal4. Although Gal4 is required to bring Rad6 to the promoter, we do not know how Rad6 is displaced. In the absence of H2B ubiquitylation, Rad6 is still recruited to the GAL UAS, but its turnover is slightly delayed (Fig. 1C). Perhaps the ubiquitylated template itself plays a role in releasing Rad6 from the GAL promoter. Alternatively, the recruitment of SAGA might contribute to the displacement of Rad6.

Rad6 not only appears to precede SAGA at the GAL1 UAS, but it also binds transiently whereas SAGA binds stably. What is the significance of the different binding patterns between the two factors? We propose that the temporal difference in promoter association, which results in the staged recruitment of Rad6 and SAGA, provides a mechanism, first, to ubiquitylate $\mathrm{H} 2 \mathrm{~B}$ through Rad6-Brel and, subsequently, to deubiquitylate H2B through the Ubp8 subunit of SAGA (Henry et al. 2003). This would restrict both the period of $\mathrm{H} 2 \mathrm{~B}$ ubiquitylation as well as the level of the modified histone at the GAL1 promoter, two conditions that we have previously shown to be important for the optimal transcription of GAL1 (Henry et al. 2003). The transience of Rad6 promoter association might also contribute to the limited period and level of $\mathrm{H} 2 \mathrm{~B}$ ubiquitylation. SAGA, on the other hand, provides another function at the GAL1 core promoter besides deubiquitylating $\mathrm{H} 2 \mathrm{~B}$, which might account for its more stable association with the UAS. The Spt3 subunit of SAGA is required for the recruitment of TBP, and the continued presence of SAGA at the UAS could help to "tether" TBP to the core promoter during successive rounds of transcription initiation (Larschan and Winston 2001; Bhaumik and Green 2002). 


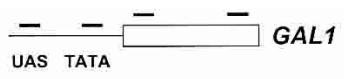

A. ChDIP: $\alpha$-Flag (H2B); $\alpha$-HA (ubiquitin)

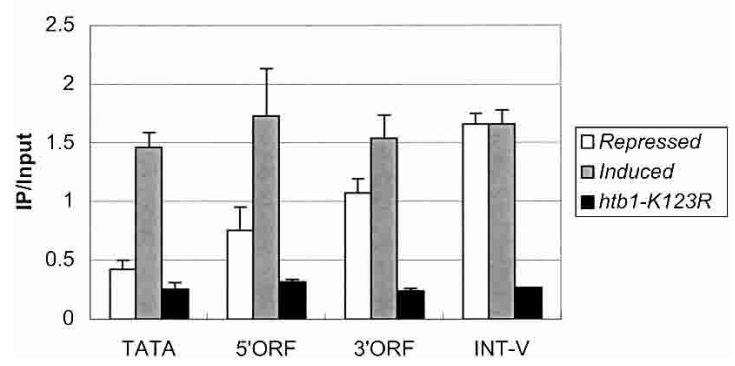

B. ChIP: $\alpha-H A$ (Rad6)

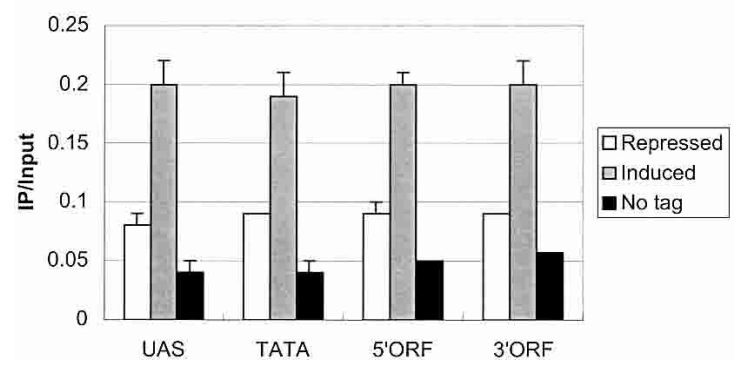

Figure 6. Ubiquitylated $\mathrm{H} 2 \mathrm{~B}$ and $\mathrm{Rad} 6$ are associated with the GAL1 promoter and ORF. (A) ChDIP was performed in the FlagHTB1 strain YKH045 during growth in YPD medium (repressed, white bars) and after galactose induction (induced, gray bars). ChDIP was also performed in the Flag-htb1-K123R strain YKH046 after galactose induction (htb1-K123R, dark gray bars). DNA was analyzed at the GAL1 TATA, 5' ORF, and 3' ORF regions by PCR in real time. The INT- $V$ sequences served as a control for media differences. $(B)$ ChIP was performed in the Rad6-HA strain YKH010 during growth in YPD medium (repressed, white bars) and after galactose induction (induced, gray bars). ChIP was also performed in the untagged control strain JR5-2A after galactose induction (No tag, dark gray bar). DNA was analyzed by PCR in real time at the GAL1 UAS and the $G A L 1$ regions described in panel $A$. The approximate location of primers used for PCR analysis is shown relative to GAL1 promoter regulatory elements and ORF.

Rad6 functions either directly or indirectly as a transcriptional repressor in silent chromatin and at the repressible $A R G 1$ gene, and this role is directly related to its activity in H2B ubiquitylation (Huang et al. 1997; Dover et al. 2002; Ng et al. 2002; Sun and Allis 2002; Turner et al. 2002). In contrast, Rad6 functions as a coactivator during galactose induction, also through its H2B ubiquitylation activity. Unlike SAGA, which is an essential coactivator at GAL1 (Bhaumik and Green 2001; Larschan and Winston 2001), Rad6 is dispensable for GAL1 transcription (data not shown). Gen5 itself is also not required for GAL1 transcription, and gcn5 5 mutants appear phenotypically similar to $h t b 1-K 123 R$ mutants with respect to their modest defect in GAL1 transcription (Fig. 7; Bhaumik and Green 2001; Larschan and Win-

ston 2001). However, the presence of ubiquitylated H2B becomes very important for GAL1 expression when the Gcn5 subunit of SAGA is absent (Fig. 7B), suggesting that Rad6-directed ubiquitylation of H2B and Gcn5-mediated acetylation of $\mathrm{H} 3$ play overlapping roles during galactose induction. Consistent with this view, GAL1 transcript levels are significantly lower in an $h t b 1$ K123R hht1-K14A double mutant compared to each single mutant (C. Hillyer, unpubl. data). We do not know

A.
PHO5

suc2
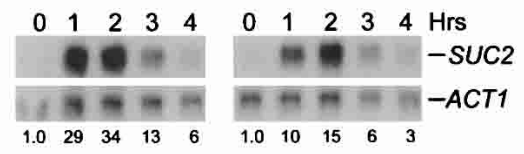

GAL1
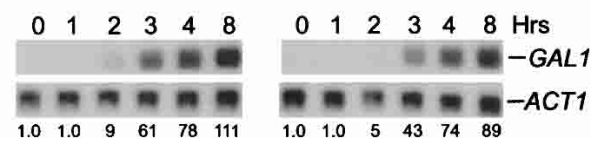

B.

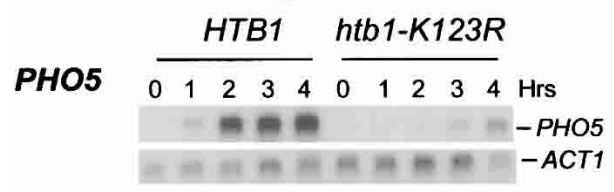

GAL1
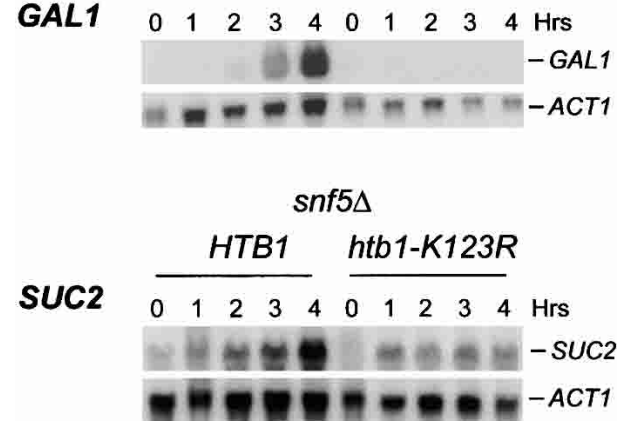

Figure 7. H2B ubiquitylation has overlapping functions with chromatin remodeling factors. $(A)$ Cells from strain JR5-2A that contained either wild-type HTB1 or the $h t b 1-K 123 R$ allele were shifted from YPD medium to: no phosphate synthetic medium (PHO5), YP medium $+2 \%$ galactose (GAL1), or YP medium $+0.05 \%$ glucose (SUC2) for the indicated times. Northern blot analysis was performed with the indicated probes. The numbers beneath each lane represent transcript levels normalized to ACT1 mRNA. (B) Northern blot analysis was performed in $g c n 5 \Delta$ (JR7-2B) or snf5 (JR16-6A) mutants that contained either wild-type $H T B 1$ or the $h t b 1-K 123 R$ allele after cells were shifted to the media described in panel $A$. The SUC2 blot was overexposed to show the effect of the $h t b 1-K 123 R$ mutation on residual SUC2 mRNA accumulation in the snf5 $\Delta$ mutant. 
what step in the galactose induction pathway is sensitive to the combined loss of H2B ubiquitylation and Gen5. The Gal4 activator binds robustly to the GAL UAS elements in an htb1-K123R gcn5s double mutant upon galactose induction; however, we have found that the Swi/ Snf complex, which is required for $G A L$ transcription in some strain backgrounds, is not recruited to the GAL1 promoter when both factors are absent (C. Hillyer, unpubl. data).

\section{H2B ubiquitylation is a mark of active chromatin}

$\mathrm{H} 2 \mathrm{~B}$ ubiquitylation is not restricted to the GAL1 promoter but is found at other actively transcribed genes as well, including the inducible PHO5 gene (Fig. 4). H2B is also transiently ubiquitylated at the $\mathrm{PHO} 5$ promoter during gene induction, and, as seen for GAL1, the period of $\mathrm{H} 2 \mathrm{~B}$ ubiquitylation precedes the maximal accumulation of PHO5 transcripts. This is consistent with the view that the $\mathrm{H} 2 \mathrm{~B}$ modification might play a general role during an early stage of gene activation. We assume, although we have not yet tested, that Rad6 ubiquitylates $\mathrm{H} 2 \mathrm{~B}$ at the PHO5 promoter when phosphate is depleted. SAGA is recruited to this promoter by the Pho4 activator, and thus the Ubp8 subunit of SAGA might also regulate the deubiquitylation of $\mathrm{H} 2 \mathrm{~B}$ during $\mathrm{PHO} 5$ activation (Barbaric et al. 2003). However, it was recently reported that SAGA-dependent hyperacetylation of nucleosomes at the $\mathrm{PHO} 5$ promoter leads to histone eviction, and this mechanism could also account for the loss of ubiquitylated H2B (Reinke and Horz 2003). Ubiquitylated H2B is also present at the promoters of the constitutively transcribed PMA1 and ACT1 genes, and Rad6 is associated with the same promoters (Fig. 6). If transient ubiquitylation of $\mathrm{H} 2 \mathrm{~B}$ plays a general role in the initiation of transcription, it is predicted that the ubiquitin moiety will be continuously turned over at constitutive as well as inducible genes. Although neither the PMA1 nor ACT1 gene is regulated by the SAGA complex, other Ubps also target $\mathrm{H} 2 \mathrm{~B}$ for deubiquitylation (C.F. Kao, unpubl. data), and these Ubps might play a role in removing the ubiquitin moiety at SAGA-independent genes.

Ubiquitylated $\mathrm{H} 2 \mathrm{~B}$ appears to be excluded from regions of silenced chromatin, just like the H3 Lys 4 and Lys 79 methylation marks that it controls (Bernstein et al. 2002; van Leeuwen et al. 2002; Ng et al. 2003a). Hypomethylation of the $\mathrm{H} 3 \mathrm{~N}$ termini is a prerequisite for Sir protein binding to silenced chromatin, and Sir binding to hypomethylated H3 N tails is postulated to block the Set 1 and Dot1 HMTases from accessing their substrates (van Leeuwen and Gottschling 2002; van Leeuwen et al. 2002; Ng et al. 2003a). Rad6 is also excluded from silent chromatin, but Sir proteins are not known to interact with the $\mathrm{H} 2 \mathrm{~B} \mathrm{C}$ tail. Thus, it could be that the structure of silenced chromatin generally inhibits Rad6 access to these regions, thereby blocking H2B ubiquitylation. Regardless, the combined data support the view that $\mathrm{H} 2 \mathrm{~B}$ ubiquitylation defines domains of active chromatin, either directly or through its role in the trans- histone regulation of histone H3 Lys 4 and Lys 79 methylation.

\section{Materials and methods}

\section{S. cerevisiae strains, plasmids, and growth conditions}

Yeast strains are all derivatives of W303-1A and are listed in Table 1. The genomic copies of the RAD6 and GCN5 genes were tagged with the triple HA epitope at their $\mathrm{C}$ termini using his5 as a marker and sequences flanking the stop codons to direct integration at the appropriate chromosomal location (Longtine et al. 1998). Integrations were confirmed by PCR analysis and by Western blot analysis with anti-HA antibodies. Gene knockouts were performed by transformation with PCR products that contained the URA3 gene flanked by 50-70 bp of DNA surrounding the ATG and stop codon of the appropriate gene. All gene knockouts were confirmed by PCR analysis and phenotypic screens. Plasmids carrying Flag-tagged HTB1 or $h t b 1-K 123 R$ genes have been previously described (Recht and Osley 1999; Robzyk et al. 2000). An HA-UBI4 gene driven by the constitutive GAPDH promoter was carried on plasmid pRG145, which was kindly provided by R. Gardner and D. Gottschling (Fred Hutchinson Cancer Research Center). This gene was integrated at the ura3-1 locus in strains carrying Flag-HTB1 or Flag-htb1$K 123 R$ after digestion with StuI, following standard genetic procedures. Expression was confirmed by Western blot analysis with anti-Flag and anti-HA antibodies.

Cells were grown at $30^{\circ} \mathrm{C}$ in YPD medium or in SD medium supplemented with appropriate amino acids and bases. For gene induction experiments, cells were washed two times with sterile water and shifted into medium containing $2 \%$ galactose for GAL1 induction, into medium containing $0.05 \%$ glucose for SUC2 induction, and into no phosphate synthetic medium for PHO5 induction (Vogel et al. 1989). For analysis of Rad6-HA and Gen5-HA GAL1 UAS association at short times after a shift to galactose-inducing conditions, cells were pregrown in YPD, washed, and resuspended in YP $+2 \%$ raffinose for $2 \mathrm{~h}$, at which point galactose was added to a final concentration of $2 \%$.

\section{RNA analysis}

Northern blot analysis was performed with 10-20 $\mu$ g of total yeast RNA extracted from cells just before $\left(0^{\prime}\right)$ and at 1 -h intervals after the shift to the appropriate medium for gene induction. Hybridization probes corresponding to the GAL1, SUC2, or PHO5 ORFs were labeled by the method of random priming. Hybridization intensities were quantitated with a Molecular Dynamics PhosphorImager.

\section{Chromatin immunoprecipitation}

Yeast strains were grown in YPD medium to an O.D.600 of 0.50.7 and then shifted to YP medium containing $2 \%$ galactose. Immediately before and at 30-min intervals up to $120 \mathrm{~min}$ after the shift, $50 \mathrm{~mL}$ of cells were removed and fixed with $1 \%$ formaldehyde at room temperature for $15 \mathrm{~min}$ for analysis of histone modifications and for 30 min for analysis of Rad6-HA and Gcn5HA binding. Fixation was stopped by the addition of glycine to $125 \mathrm{mM}$ for $5 \mathrm{~min}$, the cells were collected by centrifugation and washed two times with ice-cold TBS $(100 \mathrm{mM}$ Tris at $\mathrm{pH}$ $7.5,0.9 \% \mathrm{NaCl}$ ). After the cell pellets were quick-frozen in EtOH-dry ice, they were stored at $-80^{\circ} \mathrm{C}$. The cell pellets were thawed on ice, resuspended in $500 \mu \mathrm{L}$ of FA lysis buffer $(50 \mathrm{mM}$ HEPES-KOH at $\mathrm{pH} 7.5,140 \mathrm{mM} \mathrm{NaCl}, 1$ mM EDTA, $1 \%$ Triton 
Table 1. S. cerevisiae strains

\begin{tabular}{|c|c|c|}
\hline Strain & Genotype & Source \\
\hline JR5-2A & $\begin{array}{l}\text { MATa htb-1-1 htb2-1 leu2-3,-112 his3-11,-15 trp1-1 ura3-1 ade2-1 can1-100 <pRS314-HTB1 or } \\
\text { pRS314-htb1-K123R> }\end{array}$ & Robzyk et al. 2000 \\
\hline$J R 7-2 B$ & $\begin{array}{l}\text { MATa htb1-1 htb2-1 leu2-3,-112 his3-11,-15 trp1-1 ura3-1 ade2-1 can1-100 gen5s::TRP1 } \\
\text { <pRS413-HTB1 or pRS413-htb1-K123R> }\end{array}$ & Recht and Osley 1999 \\
\hline JR6-16A & $\begin{array}{l}\text { MATa htb1-1 htb2-1 leu2-3,-112 his3-11,-15 trp1-1 ura3-1 ade2-1 can1-100 snf5s } \\
\quad<\text { pRS314-HTB1 or pRS314-htb1-K123R> }\end{array}$ & Recht and Osley 1999 \\
\hline YKH010 & $\begin{array}{l}\text { MATa htb1-1 htb2-1 leu2-3,-112 his3-11,-15 trp1-1 ura3-1 ade2-1 can1-100 RAD6-HA::his5 } \\
\text { <pRS314-HTB1> }\end{array}$ & This study \\
\hline YKH017 & $\begin{array}{l}\text { MATa htb1-1 htb2-1 leu2-3,-112 his3-11,-15 trp1-1 ura3-1 ade2-1 can1-100 RAD6-HA::his5 } \\
\text { <pRS314-htb1-K123R> }\end{array}$ & This study \\
\hline YKH012 & $\begin{array}{l}\text { MATa htb1-1 htb2-1 leu2-3,-112 his3-11,-15 trp1-1 ura3-1 ade2-1 can1-100 GCN5-HA::his5 } \\
\text { <pRS314-HTB1> }\end{array}$ & Henry et al. 2003 \\
\hline YKH019 & $\begin{array}{l}\text { MATa htb1-1 htb2-1 leu2-3,-112 his3-11,-15 trp1-1 ura3-1 ade2-1 can1-100 GCN5-HA::his5 } \\
\text { <pRS314-htb1-K123R> }\end{array}$ & This study \\
\hline YKH045 & $\begin{array}{l}\text { MATa htb1-1 htb2-1 leu2-3,-112 his3-11,-15 trp1-1 ura3-1 ade2-1 can1-100 } \\
\text { GAPDH::HA-UB14::URA3 <pRS314-Flag-HTB1> }\end{array}$ & Henry et al. 2003 \\
\hline YKH046 & $\begin{array}{l}\text { MATa htb1-1 htb2-1 leu2-3,-112 his3-11,-15 trp1-1 ura3-1 ade2-1 can1-100 } \\
\text { GAPDH::HA-UB14::URA3 <pRS314-Flag-htb1-K123R> }\end{array}$ & Henry et al. 2003 \\
\hline Y131 & 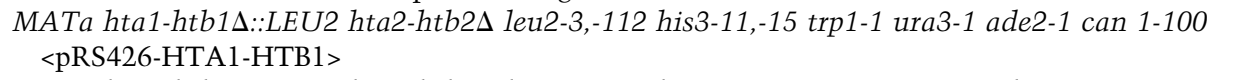 & Robzyk et al. 2000 \\
\hline Y133 & 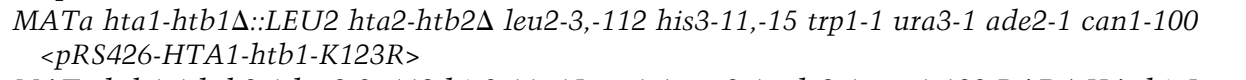 & Robzyk et al. 2000 \\
\hline YCH001 & $\begin{array}{l}\text { MATa htb1-1 htb2-1 leu2-3,-112 his3-11,-15 trp1-1 ura3-1 ade2-1 can1-100 RAD6-HA::his5 } \\
\text { gal4D::URA3 <pRS314-HTB1> }\end{array}$ & This study \\
\hline YCH0O2 & $\begin{array}{l}\text { MATa htb1-1 htb2-1 leu2-3,-112 his3-11,-15 trp1-1 ura3-1 ade2-1 can1-100 RAD6-HA::his5 } \\
\text { bre1D::URA3 <pRS314-HTB1> }\end{array}$ & This study \\
\hline YCH003 & $\begin{array}{l}\text { MATa htb1-1 htb2-1 leu2-3,-112 his3-11,-15 trp1-1 ura3-1 ade2-1 can1-100 RAD6-HA::his5 } \\
\text { gen5A::URA3 <pRS314-HTB1> }\end{array}$ & This study \\
\hline
\end{tabular}

$\mathrm{X}-100,0.1$ sodium deoxycholate, $1 \mathrm{mM}$ PMSF) supplemented with a fresh protease inhibitor cocktail (Sigma), and lysed by vortexing with glass beads for $15 \mathrm{~min}$ at $4^{\circ} \mathrm{C}$. The cell lysates were sonicated six times for $10 \mathrm{sec}$ each on a Branson Sonifier 250 set at $30 \%$ output and $100 \%$ duty cycle, with $30 \mathrm{sec}$ cooling between each sonication cycle. The average size of the DNA fragments produced was between 300 and 500 bp. Following centrifugation at $15 \mathrm{~K}$ for $30 \mathrm{~min}$ at $4^{\circ} \mathrm{C}$ in a microfuge, the solubilized chromatin was transferred to a fresh microfuge tube, and the volume was adjusted to $1 \mathrm{~mL}$ with FA lysis buffer. For analysis of input chromatin, $50-100 \mu \mathrm{L}$ were removed.

For analysis of Rad6-HA and Gen5-HA chromatin immunoprecipitations, $2-5 \mu$ l of anti-HA antibody (12CA5; Roche) were added to $\sim 20$ O.D. equivalents of solubilized chromatin and incubation was continued overnight at $4^{\circ} \mathrm{C}$. Immune precipitates were collected by a 2 -h incubation at $4^{\circ} \mathrm{C}$ with $40 \mu \mathrm{L}$ of protein G sepharose beads (Amersham) equilibrated with FA lysis buffer and protease inhibitors. The beads were washed sequentially with $1.4 \mathrm{~mL}$ FA-lysis buffer, $1.4 \mathrm{~mL}$ FA-lysis buffer $+0.5 \mathrm{M} \mathrm{NaCl}, 1.4 \mathrm{~mL} \mathrm{LiCl}$ solution (10 mM Tris at $\mathrm{pH} 8$, $250 \mathrm{mM} \mathrm{LiCl}, 0.5 \% \mathrm{NP}-40,0.5 \%$ deoxycholate, $1 \mathrm{mM}$ EDTA), and $1.4 \mathrm{~mL} \mathrm{TE}(\mathrm{pH} 8)$ for $5 \mathrm{~min}$ each at $4^{\circ} \mathrm{C}$, and the immune complexes were eluted twice at room temperature with $250 \mu \mathrm{L}$ of $1 \%$ SDS, $0.1 \mathrm{M} \mathrm{NaCO}_{3}$.

Chromatin double immunoprecipitation (ChDIP) to detect ubiquitylated $\mathrm{H} 2 \mathrm{~B}$ was carried out in strains YKH045 (FlagHTB1; HA-UBI4) and YKH046 (Flag-htb1-K123R; HA-UBI4) by the method outlined in Henry et al. (2003), with the following modifications. One hundred microliters of M2 agarose beads (Sigma) equilibrated in FA lysis buffer were incubated with 40 O.D. equivalents of solubilized chromatin overnight at $4^{\circ} \mathrm{C}$, the beads were collected by centrifugation and washed four times with FA lysis buffer, and the immune complexes were eluted with $500 \mu \mathrm{L}$ FA lysis buffer containing $200 \mu \mathrm{g} / \mathrm{mL} 3 \times$ Flag peptide (Sigma) overnight at $4^{\circ} \mathrm{C}$. One-tenth of the eluate was reserved for "input", and anti-HA antibody (12C5A, Roche) was added to a final concentration of $15 \mu \mathrm{g} / \mathrm{mL}$ to the remaining eluate, followed by incubation at $4{ }^{\circ} \mathrm{C}$ overnight. The immune complexes were collected by incubation with $80 \mu \mathrm{L}$ protein G sepharose beads (Amersham) for $3-5 \mathrm{~h}$ at $4^{\circ} \mathrm{C}$ and the beads were washed as described above. The beads were resuspended in 100 $\mu \mathrm{L}$ TE (pH 8) with $20 \mu \mathrm{g}$ RnaseA (Sigma) and incubated at $37^{\circ} \mathrm{C}$ for $30 \mathrm{~min}$. Following a wash with $1 \mathrm{~mL} \mathrm{TE}$, the immune complexes were eluted from the beads by sequential incubation in $500 \mu \mathrm{L}$ of $1 \% \mathrm{SDS} / 50 \mathrm{mM}$ Tris $\left(\mathrm{pH}\right.$ 8) for $5 \mathrm{~min}$ at $100^{\circ} \mathrm{C}$ and for 10 min at $65^{\circ} \mathrm{C}$. After adjusting the $\mathrm{NaCl}$ concentration in each sample to $0.2 \mathrm{M}$, the cross-links were reversed by incubation at $65^{\circ} \mathrm{C}$ overnight. DNA was extracted according to published procedures (Hecht et al. 1996; Kuo and Allis 1999) and resuspended in $100 \mu \mathrm{L}$ TE ("input") or $25 \mu \mathrm{TE}$ ("IP").

\section{PCR analysis}

Quantitative PCR in real time was performed using a SYBR Green master mix and an ABI 7000 Prism Sequence Detection system, both from Applied Biosystems. Triplicate samples containing $5 \mu \mathrm{L}$ of 1:20-1:100 diluted IP DNA and 1:500-1:1000 diluted input DNA were analyzed, and all reactions were performed in the linear range of amplification. PCR primers were designed using the software program Primer Express (ABI). An intergenic sequence on chromosome $\mathrm{V}(I N T-V)$ that is not regulated by carbon source or low phosphate served as an internal control. Conventional PCR was carried out with $5 \mu \mathrm{L}$ of IP DNA 
and typically $5 \mu \mathrm{L}$ of 1:50 diluted input DNA, using a MJ Research Thermocycler. PCR products were separated on a $10 \%$ polyacrylamide-SDS gel, which was stained with ethidium bromide and photographed on a Nucleotech gel documentation system.

\section{Acknowledgments}

We thank Sarah Gladden, Rebecca Hamel, Kim Johnson, and Jennifer Weissblum for their expert technical assistance, and Dana Underwood is acknowledged for her comments on the manuscript. Richard Gardner and Dan Gottschling are gratefully acknowledged for their generous gift of plasmid pRG145, and $\mathrm{Zu}-\mathrm{Wen}$ Sun is thanked for his advice on the elution of Flag-H2B from fixed chromatin. Supported by NIH grants GM40118 (M.A.O.) and GM55360 (S.L.B.) and NSF grant MCB0078940 (S.L.B.). K.W.H. was supported by NIH grant CA09171 (Training Program in Basic Cancer Research to The Wistar Institute).

The publication costs of this article were defrayed in part by payment of page charges. This article must therefore be hereby marked "advertisement" in accordance with 18 USC section 1734 solely to indicate this fact.

\section{References}

Barbaric, S., Reinke, H., and Horz, W. 2003. Multiple mechanistically distinct functions of SAGA at the PHO5 promoter. Mol. Cell. Biol. 23: 3468-3476.

Barsoum, J. and Varshavsky, A. 1985. Preferential localization of varient nucleosomes near the $5^{\prime}$ end of the mouse dihydrofolate reductase gene. J. Biol. Chem. 260: 7688-7697.

Belotserkovskaya, R. and Berger, S.L. 1999. Interplay between chromatin modifying and remodeling complexes in transcriptional regulation. Crit. Rev. Eukaryot. Gene Expr. 9: 221-230.

Bernstein, B.E., Humphrey, E.L., Erlich, R.L., Schneider, R., Bouman, P., Liu, J.S., Kouzarides, T., and Schreiber, S.L. 2002. Methylation of histone H3 Lys 4 in coding regions of active genes. Proc. Natl. Acad. Sci. 99: 8695-8700.

Bhaumik, S.R. and Green, M.R. 2001. SAGA is an essential in vivo target of the yeast acidic activator Gal4p. Genes \& Dev. 15: $1935-1945$.

- 2002. Differential requirement of SAGA components for recruitment of TATA-box-binding protein to promoters in vivo. Mol. Cell. Biol. 22: 7365-7371.

Bohm, L., Crane-Robinson, C., and Sautiere, P. 1980. Proteolytic digestion studies of chromatin core-histone structure. Identification of a limit peptide of histone H2A. Eur. J. Biochem. 106: 525-530.

Borts, R.H., Lichten, M., and Haber, J.E. 1986. Analysis of meiosis-defective mutations in yeast by physical monitoring of recombination. Genetics 113: 551-567.

Bradbury, E.M. 1992. Reversible histone modifications and the chromosome cell cycle. Bioessays 14: 9-16.

Briggs, S.D., Xiao, T., Sun, Z.W., Caldwell, J.A., Shabanowitz, J., Hunt, D.F., Allis, C.D., and Strahl, B.D. 2002. Gene silencing: Trans-histone regulatory pathway in chromatin. Nature 418: 498.

Bryant, G.O. and Ptashne, M. 2003. Independent recruitment in vivo by Gal4 of two complexes required for transcription. Mol. Cell 11: 1301-1309.

Busch, H. and Goldknopf, I.L. 1981. Ubiquitin-protein conjugates. Mol. Cell. Biochem. 40: 173-187.
Carrozza, M.J., John, S., Sil, A.K., Hopper, J.E., and Workman, J.L. 2002. Gal80 confers specificity on HAT complex interactions with activators. J. Biol. Chem. 277: 24648-24652.

Davie, J.R., Lin, R., and Allis, C.D. 1991. Timing of the appearance of ubiquitinated histones in developing new macronuclei of Tetrahymena thermophila. Biochem. Cell Biol. 69: 66-71.

Dohmen, R.J., Madura, K., Bartel, B., and Varshavsky, A. 1991. The N-end rule is mediated by the UBC2(RAD6) ubiquitinconjugating enzyme. Proc. Natl. Acad. Sci. 88: 7351-7355.

Dover, J., Schneider, J., Tawiah-Boateng, M.A., Wood, A., Dean, K., Johnston, M., and Shilatifard, A. 2002. Methylation of histone $\mathrm{H} 3$ by COMPASS requires ubiquitination of histone H2B by Rad6. J. Biol. Chem. 277: 28368-28371.

Dudley, A.M., Rougeulle, C., and Winston, F. 1999. The Spt components of SAGA facilitate TBP binding to a promoter at a post-activator-binding step in vivo. Genes \& Dev. 13: 2940-2945.

Grunstein, M. 1997. Histone acetylation in chromatin structure and transcription. Nature 389: 349-352.

Hassan, A.H., Neely, K.E., Vignali, M., Reese, J.C., and Workman, J.L. 2001. Promoter targeting of chromatin-modifying complexes. Front. Biosci. 6: D1054-D1064.

Hecht, A., Strahl-Bolsinger, S., and Grunstein, M. 1996. Spreading of transcriptional repressor SIR3 from telomeric heterochromatin. Nature 383: 92-96.

Henry, K.W. and Berger, S.L. 2002. Trans-tail histone modifications: Wedge or bridge? Nat. Struct. Biol. 9: 565-566.

Henry, K., Wyce, A., Lo, W.S., Duggan, L., Emre, N.C., Kao, C.F., Pillus, L., Shilatifard, A., Osley, M.A., and Berger, S.L. 2003. Transcriptional activation via sequential histone H2B ubiquitylation and deubiquitylation, mediated by SAGA-associated Ubp8. Genes \& Dev. 17: 2648-2663.

Hensold, J.O., Swerdlow, P.S., and Housman, D.E. 1988. A transient increase in histone $\mathrm{H} 2 \mathrm{~A}$ ubiquitination is coincident with the onset of erythroleukemic cell differentiation. Blood 71: 1153-1156.

Hoege, C., Pfander, B., Moldovan, G.L., Pyrowolakis, G., and Jentsch, S. 2002. RAD6-dependent DNA repair is linked to modification of PCNA by ubiquitin and SUMO. Nature 419: 135-141.

Huang, H., Kahana, A., Gottschling, D.E., Prakash, L., and Liebman, S.W. 1997. The ubiquitin-conjugating enzyme Rad6 (Ubc2) is required for silencing in Saccharomyces cerevisiae. Mol. Cell. Biol. 17: 6693-6699.

Hwang, W.W., Venkatasubrahmanyam, S., Ianculescu, A.G., Tong, A., Boone, C., and Madhani, H.D. 2003. A conserved RING finger protein required for histone H2B monoubiquitination and cell size control. Mol. Cell 11: 261-266.

Jason, L.J., Moore, S.C., Lewis, J.D., Lindsey, G., and Ausio, J. 2002. Histone ubiquitination: A tagging tail unfolds? Bioessays 24: 166-174.

Jentsch, S., McGrath, J.P., and Varshavsky, A. 1987. The yeast DNA repair gene RAD6 encodes a ubiquitin-conjugating enzyme. Nature 329: 131-134.

Joazeiro, C.A. and Weissman, A.M. 2000. RING finger proteins: Mediators of ubiquitin ligase activity. Cell 102: 549-552.

Johnston, M. and Carlson, M. 1992. Regulation of carbon and phosphate utilization. In The molecular and cellular biology of the yeast Saccharomyces; Gene expression, pp. 193-281. Cold Spring Harbor Laboratory Press, Cold Spring Harbor, NY.

Johnston, M., Flick, J.S., and Pexton, T. 1994. Multiple mechanisms provide rapid and stringent glucose repression of GAL gene expression in Saccharomyces cerevisiae. Mol. Cell. Biol. 14: 3834-3841. 
Kaplun, L., Ivantsiv, Y., Kornitzer, D., and Raveh, D. 2000. Functions of the DNA damage response pathway target Ho endonuclease of yeast for degradation via the ubiquitin-26S proteasome system. Proc. Natl. Acad. Sci. 97: 10077-10082.

Kornitzer, D., Raboy, B., Kulka, R.G., and Fink, G.R. 1994. Regulated degradation of the transcription factor Gen4. $E M B O$ J. 13: 6021-6030.

Kuo, M.H. and Allis, C.D. 1999. In vivo cross-linking and immunoprecipitation for studying dynamic Protein:DNA associations in a chromatin environment. Methods 19: 425-433.

Kuo, M.H., vom Baur, E., Struhl, K., and Allis, C.D. 2000. Gen4 activator targets Gen5 histone acetyltransferase to specific promoters independently of transcription. Mol. Cell 6: 13091320.

Larschan, E. and Winston, F. 2001. The S. cerevisiae SAGA complex functions in vivo as a coactivator for transcriptional activation by Gal4. Genes \& Dev. 15: 1946-1956.

Levinger, L. and Varshavsky, A. 1982. Selective arrangement of ubiquitinated and D1 protein-containing nucleosomes within the Drosophila genome. Cell 28: 375-385.

Longtine, M.S., McKenzie III, A., Demarini, D.J., Shah, N.G., Wach, A., Brachat, A., Philippsen, P., and Pringle, J.R. 1998. Additional modules for versatile and economical PCR-based gene deletion and modification in Saccharomyces cerevisiae. Yeast 14: 953-961.

Melcher, K. and Johnston, S.A. 1995. GAL4 interacts with TATA-binding protein and coactivators. Mol. Cell. Biol. 15: 2839-2848.

Montelone, B.A., Prakash, S., and Prakash, L. 1981. Recombination and mutagenesis in rad6 mutants of Saccharomyces cerevisiae: Evidence for multiple functions of the RAD6 gene. Mol. Gen. Genet. 184: 410-415.

Mueller, R.D., Yasuda, H., Hatch, C.L., Bonner, W.M., and Bradbury, E.M. 1985. Identification of ubiquitinated histones 2A and 2B in Physarum polycephalum. Disappearance of these proteins at metaphase and reappearance at anaphase. J. Biol. Chem. 260: 5147-5153.

Ng, H.H., Xu, R.M., Zhang, Y., and Struhl, K. 2002. Ubiquitination of histone H2B by Rad6 is required for efficient Dot1mediated methylation of histone H3 lysine 79. J. Biol. Chem. 277: 34655-34657.

Ng, H.H., Ciccone, D.N., Morshead, K.B., Oettinger, M.A., and Struhl, K. 2003a. Lysine-79 of histone H3 is hypomethylated at silenced loci in yeast and mammalian cells: A potential mechanism for position-effect variegation. Proc. Natl. Acad. Sci. 100: 1820-1825.

Ng, H.H., Robert, F., Young, R.A., and Struhl, K. 2003b. Targeted recruitment of Set1 histone methylase by elongating Pol II provides a localized mark and memory of recent transcriptional activity. Mol. Cell 11: 709-719.

Nickel, B.E., Allis, C.D., and Davie, J.R. 1989. Ubiquitinated histone $\mathrm{H} 2 \mathrm{~B}$ is preferentially located in transcriptionally active chromatin. Biochemistry 28: 958-963.

Orlando, V. and Paro, R. 1993. Mapping Polycomb-repressed domains in the bithorax complex using in vivo formaldehyde cross-linked chromatin. Cell 75: 1187-1198.

Peterson, C.L. and Workman, J.L. 2000. Promoter targeting and chromatin remodeling by the SWI/SNF complex. Curr. Opin. Genet. Dev. 10: 187-192.

Pickart, C.M. 2001. Mechanisms underlying ubiquitination. Annu. Rev. Biochem. 70: 503-533.

Recht, J. and Osley, M.A. 1999. Mutations in both the structured domain and N-terminus of histone $\mathrm{H} 2 \mathrm{~B}$ bypass the requirement for Swi-Snf in yeast. EMBO J. 18: 229-240.

Reinke, H. and Horz, W. 2003. Histones are first hyperacetylated and then lose contact with the activated $\mathrm{PHO} 5$ pro- moter. Mol. Cell 11: 1599-1607.

Robzyk, K., Recht, J., and Osley, M.A. 2000. Rad6-dependent ubiquitination of histone H2B in yeast. Science 287: 501504.

Sanders, S.L., Jennings, J., Canutescu, A., Link, A.J., and Weil, P.A. 2002. Proteomics of the eukaryotic transcription machinery: Identification of proteins associated with components of yeast TFIID by multidimensional mass spectrometry. Mol. Cell. Biol. 22: 4723-4738.

Santos-Rosa, H., Schneider, R., Bannister, A.J., Sherriff, J., Bernstein, B.E., Emre, N.C., Schreiber, S.L., Mellor, J., and Kouzarides, T. 2002. Active genes are tri-methylated at K4 of histone H3. Nature 419: 407-411.

Seale, R.L. 1981. Rapid turnover of the histone-ubiquitin conjugate, protein A24. Nucleic Acids Res. 9: 3151-3158.

Spencer, V.A. and Davie, J.R. 1999. Role of covalent modifications of histones in regulating gene expression. Gene 240: 112.

Strahl, B.D., Ohba, R., Cook, R.G., and Allis, C.D. 1999. Methylation of histone $\mathrm{H} 3$ at lysine 4 is highly conserved and correlates with transcriptionally active nuclei in Tetrahymena. Proc. Natl. Acad. Sci. 96: 14967-14972.

Sun, Z.W. and Allis, C.D. 2002. Ubiquitination of histone H2B regulates $\mathrm{H} 3$ methylation and gene silencing in yeast. $\mathrm{Na}$ ture 418: 104-108.

Sung, P., Prakash, S., and Prakash, L. 1988. The RAD6 protein of Saccharomyces cerevisiae polyubiquitinates histones, and its acidic domain mediates this activity. Genes \& Dev. 2: 1476-1485.

Svaren, J. and Horz, W. 1997. Transcription factors vs. nucleosomes: Regulation of the PHO5 promoter in yeast. Trends Biochem. Sci. 22: 93-97.

Swerdlow, P.S., Schuster, T., and Finley, D. 1990. A conserved sequence in histone $\mathrm{H} 2 \mathrm{~A}$ which is a ubiquitination site in higher eucaryotes is not required for growth in Saccharomyces cerevisiae. Mol. Cell. Biol. 10: 4905-4911.

Trumbly, R.J. 1992. Glucose repression in the yeast Saccharomyces cerevisiae. Mol. Microbiol. 6: 15-21.

Turner, S.D., Ricci, A.R., Petropoulos, H., Genereaux, J., Skerjanc, I.S., and Brandl, C.J. 2002. The E2 ubiquitin conjugase Rad6 is required for the $\mathrm{ArgR} / \mathrm{Mcm} 1$ repression of ARG1 transcription. Mol. Cell. Biol. 22: 4011-4019.

van Leeuwen, F. and Gottschling, D.E. 2002. Genome-wide histone modifications: Gaining specificity by preventing promiscuity. Curr. Opin. Cell Biol. 14: 756-762.

van Leeuwen, F., Gafken, P.R., and Gottschling, D.E. 2002. Dot $1 p$ modulates silencing in yeast by methylation of the nucleosome core. Cell 109: 745-756.

Vogel, K., Horz, W., and Hinnen, A. 1989. The two positively acting regulatory proteins $\mathrm{PHO} 2$ and $\mathrm{PHO} 4$ physically interact with PHO5 upstream activation regions. Mol. Cell. Biol. 9: 2050-2057.

West, M.H. and Bonner, W.M. 1980. Histone 2B can be modified by the attachment of ubiquitin. Nucleic Acids Res. 8: 46714680.

Wood, A., Krogan, N.J., Dover, J., Schneider, J., Heidt, J., Boateng, M.A., Dean, K., Golshani, A., Zhang, Y., Greenblatt, J.F., et al. 2003. Bre1, an E3 ubiquitin ligase required for recruitment and substrate selection of Rad6 at a promoter. Mol. Cell 11: 267-274.

Wu, R.S., Kohn, K.W., and Bonner, W.M. 1981. Metabolism of ubiquitinated histones. J. Biol. Chem. 256: 5916-5920. 


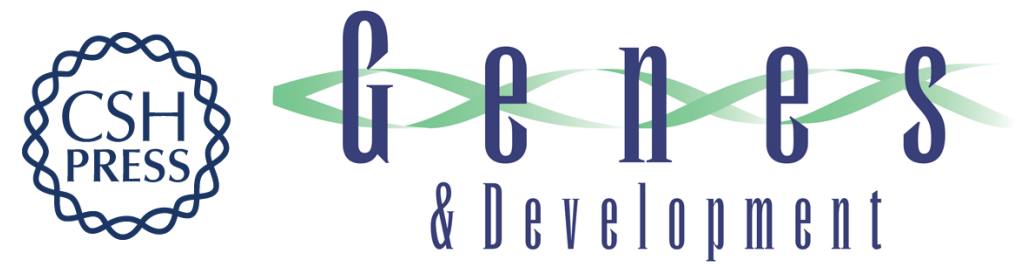

\section{Rad6 plays a role in transcriptional activation through ubiquitylation of histone H2B}

Cheng-Fu Kao, Cory Hillyer, Toyoko Tsukuda, et al.

Genes Dev. 2004, 18:

Access the most recent version at doi:10.1101/gad.1149604

References This article cites 67 articles, 29 of which can be accessed free at: http://genesdev.cshlp.org/content/18/2/184.full.html\#ref-list-1

License

Email Alerting Receive free email alerts when new articles cite this article - sign up in the box at the top Service right corner of the article or click here.

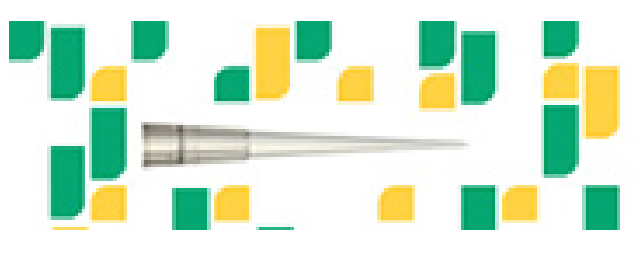

Focused on your science. 